\title{
Toward a Network Sociality
}

\section{Introduction}

In this essay I want to introduce the phenomenon and concept of a network sociality. ${ }^{1}$ The term network sociality can be understood in contrast to 'community'. Community entails stability, coherence, embeddedness, and belonging. It involves strong and longlasting ties, proximity and a common history or narrative of the collective. Network sociality stands counterposed to Gemeinschaft. It does not represent belonging but integration and disintegration. It is a disembedded intersubjectivity that is somehow 'lifted out'. (Giddens, 1984) It is an immediate intersubjectivity that is integral to what Rem Koolhaas calls the 'generic city'. (OMA, 1995). It is the social expression of a 'liquid modernity’. (Bauman, 2000) In network sociality social relations are not 'narrational' but informational; they are not based on mutual experience or common history, but primarily on an exchange of data and on 'catching up'. Narratives are characterised by duration, whereas information is defined by ephemerality. Network sociality consists of fleeting and transient, yet iterative social relations; of ephemeral but intense encounters. Narrative sociality often took place in bureaucratic organisations. In network sociality the social bond at work is not bureaucratic but informational; it is created on a project by project basis, by the movement of ideas, the establishment of only ever temporary standards and protocols, and the creation and protection of proprietory information. Network sociality is not characterised by a separation but by a combination of both work and play. It is constructed on the grounds of communication and transport technology. Network sociality, I suspect, is emerging alongside - and in some respects displacing - the community based sociality Richard Sennett (1998) talks about. ${ }^{2}$

As the title indicates, the theoretical precursor of this concept is Manuel Castells' (1996) notion of a 'network society'. Castells' main concern is the outline of global macrosociology of the information age. On the one hand networks are comprised of subjects and technologies, and on the other the links between. They are open structures, able to expand almost without limits, and they are highly dynamic. As such, networks are 'appropriate instruments for a capitalist economy based on innovation, globalisation and decentralised concentration', and also for a 'culture of endless deconstruction and reconstruction'. (Castells, 1996: 470) I think it is worthwhile translating this macrosociology of a network society into a micro-sociology of the information age. That is to say not to focus on networks themselves, but on the making of networks. What kind of sociality is at stake in the information age?

\footnotetext{
${ }^{1}$ Many thanks to Scott Lash. The main arguments of this paper emerged as a result of a dialog with him.

${ }^{2}$ Sennett (1998) provides a strong ethnographic example for both kinds of sociality, separated by one generation only. Rico's social life has all the features of what can be understood as network sociality. His life is the life of a contemporary businessman being mostly on the move. His father's social life however is clearly based on community, on 'Gemeinschaft'.
} 
My interest in the phenomenon of a network sociality shares certain objectives with mainstream social network analysis (Burt, 1980), yet differs widely from the latter in its approach. Firstly, standard network analysis features quantitative research, while my approach is based on an ethnographic perspective. Secondly, I am neither concerned with networks themselves and with the mathematics of their formal properties, nor with the uncovering of models of social relations, but rather with the making of networks, with networking as a practice. How do people build, maintain and alter these social ties? What means, tactics and strategies do they employ? What kind of cultural capital do they need to increase their social capital? Bourdieu (1986), who originated the notion of 'social capital' has consistently analysed the reproduction of more traditional social relations. How crucial is such social capital in the new informational fields that involve not the reproduction but the production of social relations. (Touraine, 1992)

I will argue with Rosi Braidotti (1994: 5) that 'in-depth transformations of the system of economic production also alter traditional social structures'. The rise of a network sociality is closely related to what has been called 'late capitalism' (Mandel, 1973; Jameson, 1991), 'new capitalism' (Sennett, 1998), or most recently ‘the new economy' (Castells, 2000; Dyson, 1998; Gilder, 2000; Kelly, 1999; Leadbeater, 1999; Shapiro and Varian, 1998) or the 'weightless economy' (Giddens, 2001). It is connected to Foucault's concept of biopower and to what Michael Hardt and Antonio Negri (2000: xv) call 'Empire', a form of sovereignty that 'operates on all registers of the social order extending down to the depths of the social world.' Furthermore, the rise of a network sociality is related to the development of information and communication technologies, to the processes of globalisation and individualisation, and to the fact that 'modern society is society on the move' (Lash and Urry, 1994: 252).

I've suggested a rise of network sociality. Note the term rise. Indicated here is a process and this process has historical roots and it has limitations in terms of geography, class and industrial sectors. Firstly this process is not new. Indeed its historical roots are fairly old. Some features of network sociality have already been described in the first half of the last centrury by cultural theorists like Georg Simmel and Walter Benjamin. However, as I will argue in the latter part of this essay, the rise of network sociality is not only a far broader and more visible phenomenon than it was a few generations ago, it is also new in terms of its formalisation and institutionalisation, and in terms of a somehow unashamed commodification of social relationships. Secondly the rise of a network sociality is especially visible in urban (post)industrial spaces and milieus. It is most visible among the new middle class of culturally educated and media and computer literate people.

One of the fields where this network sociality is particularly visible is the cultural industry, especially the field of new media. The arguments presented here are informed by a two-year research project on the emergence of the new media industry in London. ${ }^{3}$ Also most of the examples used to illustrate these arguments are taken from this research. However the networking practices described below, are not merely a phenomenon of the new media field. They are paradigmatic more widely of the information society. This

\footnotetext{
3 'Silicon Alleys: Networks of Virtual Objects', so the title of the research project (Scott Lash, Dede Boden, Celia Lury, Dan Shapiro, and Andreas Wittel), was part of the ESRC 'Virtual Society?' programme. It started in March 1998.
} 
essay is meant to be read as an attempt to explore a cultural hypothesis. It is in three main parts. In the first part I want to introduce some examples that document the rise of a network sociality. The second part consists of a critique of some theoretical accounts on contemporary transformations of sociality. The third part is an attempt to outline the concept of network sociality.

\section{The phenomenon}

\section{Example 1: new media industry as social network}

A few years ago, new media - the convergence of information and communication technology, old media, art and design - started to emerge as a rapidly growing sector of the information society. New Media, like all cultural industries, is predominantly an urban phenomenon. (Indergaard; 2000; Pratt, 1998; Scott, 1997; Zukin, 1995) It started as an industrial sector but soon was more. It became a business service for the whole industry. Probably all big players in every industrial sector now have a new media division and the SMEs at least have a few employees with new media skills. The new media field leads and supports the economy in its preparation for the digital age. It is about to transform the economy into what recently has been called 'new economy'. (Castells, 2000; Dyson, 1998; Gilder, 2000; Kelly, 1999; Leadbeater, 1999; Shapiro and Varian, 1998) This economical transformation includes a transformation of working practices. Or to sharpen this point: working practices become increasingly networking practices.

Whereas the structure of traditional industrial sectors is represented to a large extent by physicality and materiality (products, machinery, plants, transport and delivery systems), the structure of the net sector can best be understood by looking at work relations and the process of networking as social practice. ${ }^{4}$ Indeed, the specificity of the net sector as industry is that it is mainly created on the grounds of social relations, as a bottom-up network. In the case of New York, Indergaard (2000) and Pratt (1998) both present a detailed analysis of the making of 'Silicon Alley'. They persuasively show how Manhattan's new media industry is socially constructed on the grounds of networks and networking practices. The same is true for London's new media industry.

'In the cyberspace economy, the commodification of goods and services becomes secondary to the commodification of human relationships.' (Rifkin, 2000: 97) Indeed new media practitioners increasingly perceive working as networking and social relationships and networking as crucial tools and resources for a successful business. They talk about 'relationship value', claim the importance of 'networking' and have

\footnotetext{
${ }^{4}$ This is not to say that the new media industry is free from materiality. Many commentators (Latour, 1998; Löfgren, 2001) emphasise the materiality of the new media industry: computers, cables, modems etc. The materiality of the new media industry is then used as an argument against claims of a 'weightless' or 'light economy'. This argument is convincing to a certain extent. However it hides the fact that - compared with other industrial sectors - there is indeed a material lightness of the new media industry. For many new media firms in London and New York it has not been unusual to move location several times between 1998 and 2000. Such a frequency cannot be found in other industrial sectors. It can only be achieved because new media firms travel light; all they have to move are indeed laptops and other computer related equipment.
} 
reorganised their firms away from a focus on products towards a focus on clients, customers and users. Pehong Chen, CEO of BroadVision, was asked by WIRED magazine (June 2000: 238) what etailers do wrong. His answer:

It's smarter to try and get 30 percent of a person's lifetime value than 30 percent of today's market. Companies today deal with their customers on a troubleshooting basis, but at some point they're going to figure out that success is about building long-term relationships.

The 'Silicon Alley Reporter', one of the more influential magazines in the US market on new media and the net economy, rates once every year in a special issue the 100 most successful people of Manhattan's net sector. The ratings are based on five categories. One of them is called 'ability to network' - another indication that networking is becoming a crucial skill in the competitive market of the new economy, that the economical success of a firm is deeply intertwined with the social skills of the people working for it. Scott Kurnit (1997), the CEO and founder of the Internet portal About.com, published an article in one of Silicon Alley's newsletters with the headline: 'Creating Virtual Communities: It's the relationship that matters. ${ }^{5}$ The CEO of NCCO one of London's new media agencies - focuses on relationships and relationship technologies as a core business activity:

We have our emphasis on people. So the type of consultancy that we offer is helping clients who want to understand what networking can do for their business and how they might use the network to rebuild their business. It will be about relationships in the future. The network prioritises everything so adding value is going to be a function of differentiation in areas that are much less tangible. And the primary way of adding value is by building a relationship, which is delightful to engage in and sensitive to the consumer.

In June 2000 New York's Silicon Alley organised and performed a three-day think tank. The international managing director of BlueSky International is quoted with the following statement: 'As the world becomes more global, personal relationships become more important.' (Silicon Alley Daily, 1.6.2000). ${ }^{6}$ The causality of this statement is hardly persuasive in terms of logic. But this is not the point. What is interesting here is the fact that personal relationships are perceived as becoming more important. That is to say: Personal relationships are becoming more important in the economic field for the simple reason that more practitioners see them as a highly valuable business resource.

This relevance of relationships seems to even diminish the importance of contracts with clients. One software developer explains:

The contract kind of doesn't matter unless we were to completely screw it up or unless they were completely turning nasty as clients, and not paying us any

\footnotetext{
${ }^{5}$ Scott Kurnit has a BA in Sociology and Communications and is, although he started much later, becoming a serious challenger for portals like Yahoo and Excite. At the beginning of 2000, the traffic at About.com's website increased to 8.4 million unique visitors per month. (Silicon Alley Reporter, Feb. 2000, Issue 30: 33) 'Today, About is visited by one in five online users each month, making it one of the most popular destinations on the Net.’ (http://ourstory.about.com/index.htm)

${ }^{6}$ It would not be very difficult to list many more similar statements from high ranking new media people.
} 
money. If you've got a good client, then what you want is repeat business. In commercial terms, you either want repeat business or you want recommended business. And those are the two best kinds of business you can get because with the repeat business, you already know who you're dealing with and what the problems will be. As recommended business, the recommendation cuts both ways. If it's a client you like representing, normally they like you enough to tell you what your new clients are going to be like.

The shift from a focus on products towards a focus on users and clients is mirrored in the homepages of new media firms. In the period between 1995 and 1998 new media agencies highlighted on the homepages especially their products and services. Now most new media agencies highlight the list of clients they have. The products and services on Razorfish's web site for example are nearly hidden. However this shift from products to clients is in no respect limited to the Internet industry. It is observable in many other industrial sectors as well. This shift may be described as the ultimate step towards flexible specialisation.

The short history of business web sites indicates this shift as well. A few years ago business web sites had mainly the function of being extended PR or marketing tool. Now they are interfaces as webs of connectivity. They connect the users with the firm behind the web site. The short history of business web sites indicates a shift from representation towards connectivity and interactivity. (Wittel, Lury and Lash, 2002) Now web sites are a perfect example of what Karin Knorr Cetina (2000) calls a 'social object'.

What is suggested is that this development of interfaces into connectivity networks is much more than an online phenomenon. It would seem to be more generally a characteristic of the new economy. At stake however is not merely a change of electronic communication. At stake is a change of face-to-face interaction. This transformation can ironically be well studied in a field that is strongly associated with interface and with all forms of technologically mediated forms of communication. This real side is the practice of networking.

As already said, networking has always been an important business practice. New however seems to be the broadness of the phenomenon. Until recently this practice has been associated with the level of higher management. Now there seems to be a social trickling down effect from the level of leadership and higher management to new media's 'shop floor level'. Networking now is as much performed on the ground of the corporate world as on the top. Also new seems to be the explicit acknowledgement of the importance of networking and the perception of social relations as social capital. New seems to be the intensity of this practice. Finally and as shown in the following example, new seems to be the formalisation and the institutionalisation of this practice.

\section{Example 2: Networking events}

In London we find a broad range of networking events in the new media field. Most of these events take place once a month. All of them have been established between 1998 and 1999. Some of these networking events like 'The Cultural Entrepreneurs' Club', 'Cybersalon' and 'London Virtual Reality Group' have a close affinity with the art world, but most of them are mainly placed as part and supplement of the industry. The most well 
know is 'First Tuesday'. It started in October 1998 in a pub in London. In June 2001 'First Tuesday' had more than 100.000 members worldwide. Also it branched out from London to other big cities in the UK and even spread to cities in Europe and the US, operating in 100 cities across 46 countries. Other networking groups are called 'Digital People', 'Chemistry', 'New Media Knowledge’, 'E-Futures', 'Surfs Up', 'The Ecademy', 'NetProZ' and 'Boobnight' (Boob = bring our own beer). Additionally, women networking groups like 'Hightech-Women', 'Webgrrls' and 'E-women' emerged with the aim to conquer the male dominated world of e-business.

Some of these events are highly structured and organised. 'First Tuesday' for example, a network to connect ideas and money, entrepreneurs and venture capital, found a particularly efficient way to enforce the networking practices. Internet entrepreneurs wear green badges, investors have red badges, and service providers get yellow ones. This way nobody loses time accidentally talking to the wrong person. Other networking groups (e.g. 'Boobnight') prefer a more playful approach and focus more on laid back socialising than on a quick exchange of business cards. Some of the networks are open to everyone (NetProZ), others (Chemistry) are rather closed and work 'by invitation only'. While some of them combine networking activities with presentations or discussion groups ('The Ecademy', 'Digital People', 'E-Futures'), others focus purely on networking.

What unites all these networks however is their inherent ambivalence: On the one hand they are instrumental and functional, one the other hand they're supposed to suggest the opposite. On the one hand the commodification of social relationships (doing a pitch, getting funds, finding work) is highly obvious, on the other hand it is important to hide this commodification by creating a frame (music, alcohol etc.) that makes people comfortable, that suggests a somehow 'authentic' interest in meeting people.

According to First Tuesday (www.firsttuesday.com), networks have the same function as a 'medieval fare', they are about exchange. This idea of commodification and exchange is also expressed on the web site of the new media consultancy 'Garol', a co-organiser of 'NetProZ'. I quote from an article called 'Get more out of networks' (www.garol.com/theview):

A network is based on a key principle - the exchange of currency. We're not talking about money..., we're talking about information. Networks thrive on a complex arrangement of exchange rates and credit facitlities. To me a phone number might be nothing, but to you having it could change your life and put you in my debt. Effective networkers understand this. They play to it, offering a titbit here and a bit of advice there, then calling in the slips when they need a favour. But they are not overt about it.

At the end of the article 'Garol' comes up with seven 'top tips for managing your network'. One of them says: 'Theft: Don't steal other people's contacts. If Joe tells you about Jack, ask him to introduce you. Don't just do it yourself.' The expression 'stealing contacts' is often heard and quite common in the new media field. The idea that contacts can be stolen is necessarily based on the premise that they are commodities. 
Some of these networks establish informal rules on how to network. 'First Tuesday' for example recommends interaction with as many people as possible. It is seen as 'bad habit', one participant claims, to 'spend more than five or ten minutes with the same person'. Another regular guest describes the 'First Tuesday' evenings as

promiscuous. It is naked in showing its promiscuity. Everybody's eyes are wandering all the time. Nobody wants to miss out. It is really important to check people out as quickly as possible. In a way it's like being in a gay bar without sex.

Why does networking become such a crucial practice for the net sector? What do these institutionalised networks do? Firstly, they circulate information and knowledge, secondly they circulate capital, thirdly they circulate labour, and fourthly they circulate clients and products. The net sector is highly flexible and highly open to change, thus for the participants of this sector life and work is intrinsically insecure. Risk taking has become a necessity. Networks provide support. Thus networking reduces risk; it generates security. The bigger the networks are, the better for everyone who participates in them (Kelly, 1999).

So far, we do not have much ethnographical knowledge about the networking practices at these regular events. What are the main structural similarities and differences of these networking groups? How do the various groups articulate (doing a pitch, getting funds, finding work) and hide (music, alcohol) a commodification of social relationships? How do they address the ambivalence between the more instrumental (functional, work related) and the more purpose free (playful, authentic) aspects of this form of socializing? Should these events best be analysed as a form of social engineering? Do these gatherings have centres and peripheries? What concept of power underpins these events? How indeed do the participants network? How do they build, maintain and alter social ties? What means, tactics and strategies do they employ? There is a need for an ethnographic study of these events.

\section{Example 3: email dinner invitation}

During my fieldwork in London's new media field I received by email a dinner invitation. The text says:

Please come to a dinner at my house to celebrate, well, everything. (and I have to add you are all doing interesting and interlinking consciousness industry shenanigans but you may discover that as we go along...)

The subject line of this email has a somehow Marxist subtext: 'consciousness and food'. It is not a habit of mine to bore readers with my private life. However this invitation allows me to identify certain key characteristics inherent in network sociality. Particularly significant is the phrase in brackets.

Firstly, it suggests that the invitees of this dinner party don't know each other. The email I received was sent to nine other people and I didn't know any of the other invitees personally. Most of the names however seemed familiar to me. The host of this party mentioned these names on other occasions. During the dinner party itself I realised indeed, that none of the invitees knew each other personally. The host works for an IT company in London, has an educational background in fine art and is considerably 
involved in London's new media scene. It would have been easy for her to invite people who already know each other. So we can assume that her decision to invite people who didn't know each other was a very deliberate choice.

Secondly, the phrase in brackets informs each invitee about the work of the other participants. According to the message, we are 'all doing interesting and interlinking consciousness industry shenanigans' and, so the message continues, we will 'discover that as we go along'. What is suggested here is that we will end up talking about our work rather than our private life. Furthermore it is suggested that this practice of interlinking and exchange will be interesting and might even be useful for us, for our work and our careers. Indeed, at the dinner we did end up talking about our work. We had wonderful food, slowly but surely we got high and drunk, but we never stopped for a second to talk about ongoing and future projects, events we participated in and ideas we had, about net.art, start-up companies, and interesting web sites.

At stake here is a dinner party that is announced and presented as a networking event. This leads us to the third and most important reason why this email is of significance. Of course parties and dinner parties always work and have always worked as networking venues - from the salon of the $19^{\text {th }}$ century to contemporary business dinners on the level of higher management. Interesting in this case however is the fact that the function of the dinner party as networking event has been made explicit, that the connection between the private and the work related aspects of the dinner party has already been addressed in the invitation. Here we find again explicitness in the acknowledgement of relationships as social capital. In fact this is the only information we get in the text of this email (apart from the place and the date of the venue). Furthermore the fact, that the host of this dinner is part of the new middle classes, is another interesting example of the above mentioned trickling down effect of reflexive networking practices from the elites (whether cultural or economical elites) to the new middle classes.

\section{Example 4: Carole Stone}

The last example is quite extreme and by no means representative of the social field I talk about. However it might well be indicative in illustrating the historic transformations of sociality. It seems highly unlikely that a similar phenomenon could have been reported one or two generations ago. In April 2000 ‘The Guardian’ (6.4.2000) featured as cover story in the supplement G2 the networking practices of Carole Stone, who is according to the newspaper 'London's networking queen' and 'Britain's best connected women'. She holds monthly salons for 90 people. At least half of them are according to 'The Guardian' 'regulars in the national press'. The monthly event is 'a party to which guests come alone, safe in the knowledge that however slight their connection to her, Stone will remember their names, occupations and who in the world they would most like to meet.' Every Christmas, she gives a party where she invites 1000 guests. According to 'The Guardian' she has 13.700 friends, all filed in a database. The database informs about their marital status, their CVs, and their history of attendance. In March 2001, 'The Observer Magazine’ (18.3.2001) featured her as well. However at this stage she had 14.000 friends. This means that in less than a year she managed to make 300 new friends, which is roughly an average of one new friend every day. 
For ten years Carole Stone was the producer of BBC's radio programme 'Any Questions?' Now she runs a media consultancy business. Stone (2000) published a book called 'Networking: The Art of Making Friends'. In the prologue she says: 'Making friends is an art - an art that can be learned.' (p5) But it is also an effort: 'The effort I had to put in then is...fundamental to the art of making friends. Friends are made, they don't just happen. You have to work at it.' (p7) She defines friends as 'people you can help, and people who can help you - whether on a business or a personal level.' Again we come across the theme of instrumentality and functionality of social relations. And the theme of art, skill, effort, and work in order to establish and maintain social relations.

Stone's book is a how-to-book. 'How to go to parties with confidence and how to give them without worry, how to survive a snub and how to make successful small talk, how to network your friends and how to keep track of them all.' (p9) The latter of course is particular interesting. How to keep track of 14.000 friends? Stone:

It's like everything else we rely on in life: don't skimp on the servicing. If you do, your friendship will break down, just as the central heating boiler does when the outlook's bleak and you really need some warmth badly. Friends have to be looked after and checked up on regularly to make sure they're in good working order. (p157)

For Stone a database must be a particularly helpful tool. In her book she doesn't mention the database and how she uses it. However it is self evident that the database - let's say compared to a collection of business cards - allows a far easier way to 'nurture friends' (p160), that is to contact them on a regular basis, to 'remember their birthdays', and to write them a 'thank you note' (p161).

Lev Manovich (2001) calls databases the dominant symbolic form of the $21^{\text {st }}$ century. In contrast to the image or the novel, so Manovich, databases do not have a narrative any more; no beginning, no end, no storyline, no hierarchy. They are a collection of individual items, each of them having the same significance and the same status. Databases grow; they are never complete. Mark Poster (1995) looks from a poststructuralist perspective on databases and explores how they reposition our identities. He analyses databases as discourse (referring to Foucault's usage of discourse): they constitute subjectivity outside the immediacy of consciousness. In this respect there is a strong similarity with the panopticon. In contrast to the panopticon however databases can constitute subjectivity in absentia. Databases, so Poster continues, traverse and cancel the public/private distinction. Zygmunt Bauman (1998), taking up Poster's comparison between the database and the panopticon, points out to another difference. Whereas the panopticon is above all an instrument of the state, the database is an instrument of the market. The main purpose of the panopticon is to instill discipline, to impose a uniform pattern of behaviour, and to keep people in place. It is a weapon against difference. The database however, so Bauman says, is an instrument of separation, selection and exclusion. All three perspectives on databases suggest structural similarities with many features of network sociality.

3. Concepts of the transformation of sociality 
In the contemporary debate there are several attempts to capture the changes of sociality. I briefly want to introduce and comment on three of the more prominent concepts of current transformations of the social.

\section{Virtual Communities}

The growth of computer mediated communication has produced a rapidly growing body of literature that seeks to explore the social implications of information and communication technologies (ICT). One of the core themes of this literatures is the notion of 'virtual community'. The term has been introduced by Howard Rheingold (1994) and has been quickly picked up by the media and social scientists. (Turkle, 1995; Stone, 1995; Jones, 1997) Rheingold, like other virtual communitarians, is driven by a utopian aspiration. He starts as a critic of contemporary sociality and claims a decline of 'real' community life. He talks about 'the need for rebuilding community in the face of America's loss of a sense of a social commons' (p12). According to Rheingold, ICTs give us the chance to revitalise communities. What has been lost because of mobility and a growing relevance of consumption can now be reconstructed with a little help from a keyboard, a monitor, a processor and a modem. In cyberspace, Rheingold and others believe, we will be able to revitalise the public sphere and construct new forms of community. Most of the literature on virtual communities has been based on similar utopian and techno-deterministic perspectives.

I do not consider the concept of virtual communities to be particularly helpful in understanding the contemporary transformations of social relations. It is misleading in three ways. Firstly, this techno-deterministic perspective does not interlink cultural and technological change. The assumption, that a cultural process - the disentanglement from communities - can be reversed with technological tools, seems to be rather naïve. Or as Kevin Robins (1995: 148) puts it: 'For all its futuristic pretensions, Rheingold’s imagination is fundamentally conservative and nostalgic.'

Secondly, the usage of the term community in relation to electronic communication is at least problematic and confusing. Typically and in the tradition of Ferdinand Tönnies' view (1979), communities share a common geographic territory, a common history, a common value system, and they are rooted in a common religion. This definition of community is used by most commentators including Rheingold (1994) who observe a decline of 'real' community life. In this sense the connection between community and the Internet is an oxymoron. However talking about online interaction, virtual communitarians refer to a quite different concept of community: to one that draws on the idea of the imaginary (Anderson, 1983), and that is based on Nancy's (1991) argument that communities are always constructed, never automatic, given or natural.

Thirdly, the term virtual is misleading in that it suggests a doubling of reality. This demarcation line between a so-called virtual world and a real world has strongly shaped the debate on cyberspace and interactive media in the last few years. Virilio (1995) e.g. suggests that we are facing a 'fundamental loss of orientation...A duplication of sensible reality, into reality and virtuality, is in the making.' In contrast to this view I want to argue for a perspective that does not separate the virtual or online world from the real or offline world. In theoretical terms this emphasis on virtuality is problematic, because it suggests the existence of a real reality, a reality that is not mediated. And empirical 
research persuasively shows that emailing, online chatting, web surfing and other interactive practices are very real experiences for the people utilising them. (Miller/Slater 2000) I do not intend to suggest that there are no fundamental differences between an online and a face-to-face sociality. To mention briefly the most important difference, any online communication lacks a common and mutual perception of the context. Online sociality cannot rely on exogenous (external) or contextual forms of structuration. Thus any structuration of sociality has to be produced endogenously (internally) by the participants. However these differences do not justify a theoretical perspective that separates reality from virtual reality and thus constructs a doubling of the world.

The following two concepts are much more grounded and much more plausible than the social sci-fi construction of virtual communities.

\section{Erosion of enduring relationships}

Richard Sennett (1998) is perhaps the most prominent commentator on the decline of long-term, sustained and deep relationships. He focuses on the transformation of the organisation of work, in particular on the human consequences of the new work regime. His inquiry: how can people generate meaning and identity under the condition of increased flexibility and risks? How can they maintain lasting and trustful relationships, and how are they to create a persistent narrative in a work environment that worships change and condemns routine? In general he argues that the replacement of linear time by serial time (e.g. short term projects, short term contracts) leads to a series of losses: a loss of trust between working colleagues, to a loss of commitment towards the task in hand, and a loss of loyalty towards the organisation. It is undoubtedly ironic that in an age characterised by teamwork and corporate culture we do not see an increase of social bonds between employees but rather a weakening of them. Informal trust, so Sennett notes, requires the duration of time.

Flexibility is another feature of the short-term economy. It produces a tolerance of fragmentation and generates a lack of attachment towards work and people. Networking seems to become more important than the ability to stick to a problem and solve it. This is as true for employees with a weak work identity as it is for highly motivated employees. The really successful employees seem to avoid the 'reckonings of the accountant's bottom line. "The trick is, let nothing stick to you"' (p.79). Flexibility also affects loyalty to the company. If employees become unhappy, they are more likely to leave the organisation, rather than fight within it. And it affects skills and experience. Skills become portable and experience loses value. The ability to focus quickly on new tasks counts more than the accumulation of experience. Change becomes a value itself and resistance towards change is taken as a sign of failure. In short, short-term projects, short-term contracts, flexible tasks, and increasing fluctuation rates in organisations make it difficult for employees to develop a common narrative any more. Detachment is required, not involvement. A good team player should have the ability to stand back from established relationships. The result, so Sennett, is an erosion of deeper shared commitments, of loyalty, responsibility, and trust, of enduring and deep friendships.

In a way Sennett presents the counter story of the utopian statement of virtual communities. His observation of friendships becoming increasingly short-term and flexible is persuasive and based on empirical facts. However I hesitate to agree with the 
pessimistic undertone. His conclusion that this process jeopardizes the development of trust, commitment and loyalty seems to be debatable at least. Further more, Sennett implicitly suggests that these transformations are created by a small elite and they occur against the interests of the majority. Thus he ignores the fact that the middle classes coconstruct and actively participate within this process.

Postsocial relationships

Postsocial theory analyses the phenomenon of a disintegrating traditional social universe (Knorr Cetina, 2000). Postsocial theory has one foot in individualisation theory and another foot in actor-network theory and provides a framework for connecting both of them. Karin Knorr Cetina assesses two 'structural conditions of Western societies'. The first condition is the current process on de-socialisation, the second is that of an enormous expansion of object worlds within the social world. It is important to note that postsocial theory does not claim a decline of the social. Instead it claims a shifting of social activities away from humans and towards objects. Here I will ignore the second condition - the expansion of objects - and merely focus on the assertion of a current process of de-socialisation.

The argument of a process of de-socialisation is placed in historical context that goes back to the beginnings of industrialisation and modernity. Modernity is 'associated with the collapse of community and the onset of individualisation.' While communities have been emptied of social meanings, larger scale organisations attracted such meaning. Modernisation is seen as an expansion of social structures. Knorr Cetina claims the expansion of social structures is on hold in the contemporary climate; there is even a decline and retraction of social structures and a disintegration of community life in the private sphere. The conclusion being drawn: Social relations become flattened and thinned out.

The suggestion that there is a disintegration of a formerly strong link between communities/organisations and social life seems to be highly plausible. This is called desocialisation. However I hesitate in using this label. The historical and ongoing process of the disintegration of communities and organisations does not necessarily imply a retraction of social principles and structures. On the contrary: The example of Carole Stone seems to indicate an extension (or at least a quantification) of human interaction. Instead of perceiving this process as de-socialisation, I suggest a shift away from regimes of sociality in closed social systems and towards regimes of sociality in open social systems. Both communities and organisations are social systems with clear boundaries, with a highly defined inside and outside. Networks however are open social systems.

In the last part I attempt to outline a concept of 'network sociality' by describing some of its main dimensions.

\section{Features of a network sociality}

\section{Individualisation}

'Individualisation' presumes a removal from historically prescribed social forms and commitments, a loss of traditional security with respect to rituals, guiding norms and 
practical knowledge. (Beck, 1999) Instead individuals must actively construct social bonds. They must make decisions and order preferences. The cultural sociologist Gerhard Schulze (1993) describes a change from 'Beziehungsvorgabe' to 'Beziehungswahl', a change from pre-given relationships to choice. Pre-given relationships are not a product of personal decisions; they represent the sociality of communities. In contrast 'Beziehungswahl' is defined by a higher degree of mobility, by translocal communications, by plentyness and by affluence of social contacts, and by a subjective management of the network. A few years earlier Touraine (1988) described this transformation in a very similar way. He talks about a shift from defensive identities towards offensive identities.

In the age of individualisation identity depends increasingly on an awareness of the relations with others. (Berking, 1996) Network sociality is not based on a shared history or a shared narrative. Instead it is defined by a multitude of experiences and biographies. The new media field contains subjects with a diversity of educational and geographical backgrounds. People are, so to speak, 'lifted out' of their contexts and reinserted in largely disembedded social relations, which they must at the same time continually construct. In this respect their sociality is distanciated and immediate. (Giddens, 1990)

Knowledge workers and people in the cultural industries are 'nomadic' in their personal biography and in their non-linear work biographies. (Braidotti, 1994) They often move from one firm to another, from one occupation to another, 'mixing and matching jobs as event organisers, web site designers, ad creatives, marketing advisers, conference runners, magazine publishers, sponsorship co-ordinators, club promoters, market researchers, PR officers and various kinds of consultancy.' (Benson, 1999) To give a concrete example: In October 1998 the London based new media firm 'Okupi' had a staff of ten employees. 18 months later the number of staff was 18 employees. However only one of them has already been part of the October 1998 team. Another indicator is the growing number of freelancers. More and more people work with and for firms, but not in firms any more. Possessed with an anti-corporate ideology and a desire not to be committed to a single institution, the freelancers are paradigmatic for the work situation described by chronic network construction and maintenance. They are the most fully reliant on their own resources of social capital.

One aspect of individualisation is the DIY-biography, the active construction of one's own life (Beck and Ziegler, 1997), in this respect the active construction and reconstruction of a social network. One constantly has to renew, refresh and revalue the existing contacts. They are not taken for granted any more. That is one of the reasons why Carol Stone has to invite 90 people every month. It is the only way to keep up with 14.000 friends.

\section{Ephemeral and intense relations}

In the Internet industry as in most other industrial sectors business is increasingly organised in terms of short-term projects. As soon as a new project begins, talk (intrafirm talk as well as talk to the client) becomes intense, information moves to and fro rapidly at the same time that its wider circulation is tightly guarded. (Boden, 1994; Sennett, 1998) For the duration of the project (usually between a couple of weeks and several months) new media people work long hours and give the project first priority. 
When the project terminates, these collaborations are kept on a low flame and new projects, co-operations and social ties are established or re-established.

The tendency towards ephemeral but intense, focused, fast, and overloaded social ties is also observable in non-work situations. At parties for example the distinctive dimensions of network sociality are highly visible - the fleetingness of interactions, their intensity, and the fluctuation of social figurations. Parties are an occasion to talk to many people within only a few hours. One has to make decisions and selections between who to talk to and for how long. These decisions have to be made instantly. It would be useful sociological knowledge to find out how people make these decisions and on what grounds they select their conversation partners.

The development towards ephemeral but intense contacts is even visible in the realm of dating. For example SpeedDating, founded in 1999 in Los Angeles and since then spread to a constantly growing number of countries, provides a service that allows participants to meet ten people within 90 minutes. When the bell rings, eight minutes are reserved for each date, then the participating men and women have to rotate to another table and another person for the next date. After each date, participants fill in a yes or no answer on a rectangular card indicating whether they would like to see the person again. If a match is made, coordinators provide them with each other's phone number. (New York Times, 5.3.2000, p.35) ${ }^{7}$

The ephemerality of social contacts could be a consequence of affluence. It might be worth returning to the database of 'London's networking queen'. It is not easy to manage 14.000 friends. The conclusion that Carol Stone can't afford to spend too much time with her friends on an individual base derives from simple mathematics. The more friends one has, the less time is available for every one of them. Or an example from my own research. In February 2000 I attended a conference of new media practitioners in New York. Around 1000 people participated in this three-day event. In the evening of the last day I asked one of the participants how many new contacts he had made during the day. He replied: 'Not that many. I was a bad networker today. I got about 30 business cards.' The quote is revealing, not only because of the number of contacts made in one day according to my interlocutor a poor result. It is also indicative in another respect: He relates - or shall I say: reduces - social contacts to the exchange of business cards. At the same conference another participant explained why he was willing to pay the conference fee:

I mean the beautiful thing about New York is that a lot of people know each other, help each other, introduce each other, network ultimately. A lot of people forget you when they don't see you at these kinds of events. New York is small but at the same time it's very big as well. You live in the same area, you don't meet each other all the time, so you somehow lose contact. So these meetings and these conferences for me are about being seen and seeing other people again, saying hello, being sort of on the back of their mind and it's usually like a two-

\footnotetext{
${ }^{7}$ At the time of a revision of this paper for republication (Dec. 2004) SpeedDating has in some countries reduced the eight min. interaction to a mere three min. interaction.
} 
minute conversation like how are you doing, how is your business and that is all it needs.

Bauman (1996: 51) places these developments in a larger context: 'Everything seems to conspire these days against ...lifelong projects, lastling commitments, eternal alliances, immutable identities. One cannot build long-term hopes around one's job, profession, skills even; one can bet that, before long, the skills will cease to be in demand...one cannot build the future around partnership or the family either: in the age of 'confluent love', togetherness lasts no longer than the satisfaction of one of the partners, commitment is from the start 'until further notice', and today's intense attachment may only intensify tomorrow's frustrations.'

\section{From narrative to information}

'Information', so Lash (2001), 'is compressed in time and space. It makes no claim to universality but is contained in the immediacy of the particular. Information shrinks or compresses metanarratives to a mere point, a signal, a mere event in time.' Network sociality mirrors this distinction between the narrative and information on a microsociological level. Network sociality is not rooted in a common and shared history. As a consequence of this loss of a shared biography, subjects cannot rely on a common narrative, on shared experience. For this reason Sennett (1998) sees an erosion of enduring friendships, responsibility and trust. However this seems to be an open question. Certainly it should be worth looking at the possibility of a reconfigured trust being inscribed in informational social bonds, bonds based less in hierarchical relations and more in the complex, reciprocal intricacies of the transverse networks of information exchange. Trust here might be based less on continuous work relations of a long duration, and more on iterated work relations of a short duration; less on the knowledge of someone's character and more on the knowledge of someone's resources and his/her position in the social field. Trust here is constructed and produced as a social relation rather already pre-given or reproduced. Giddens (in Beck et al., 1994: 186) calls this 'active trust'. It is a matter of mutual influence rather than mutual fatedness. Social relations of competition too are possibly becoming informational, based on the possession and strategic deployment of proprietary knowledge. While ownership and use of some types of information are a legal matter (of contract, copyright, trademark and patent), other kinds are less formally recognised, a matter of negotiation in the practice of networking. (Lury, 1993)

To illustrate this shift from an experience based sociality to an informational sociality let me get back to SpeedDating. As mentioned, participants have only eight minutes to talk to each other before they decide whether they want to see the other person again. Within these eight minutes participants have to exchange information, not narratives. 'What do you do for a living? Where are you from? What is the most exciting thing you've ever done? What do you do in your spare time?' These are the questions to be asked according to the report in the New York Times. These questions are informational, the context resembles a job interview. It is an exchange of data rather than a romantic date.

Mobility and speed seem to be the primary reasons for this shift from a narrative or experienced based to an informational sociality. Mobility, because more and more people are on the move and thus somewhere else. In order to re-establish social contacts, 
'catching up' becomes an indispensable condition of social situations. Catching up is essentially informational. And the acceleration of speed in social encounters is additionally feeding the development towards an informational sociality. Narratives are time consuming; information is quick. A half hour business meeting is a good example to illustrate this: Participants have to get to the point as fast as possible, they have to be focused, they exchange information not stories, discourses, and narratives.

\section{Assimilation of play and work}

In network sociality professional ties become increasingly playful. Information exchange provides the infrastructure of the sector and the ability to acknowledge the rules and conventions by which the creation, distribution and protection of information occurs is crucial. Yet this does not preclude a playfulness; rather a playful attitude is frequently encouraged in the design and layout of work spaces (Goldwasser 2000), which encourage the inhabitants to introduce the unexpected into their offices, and in the use of cafes and pubs for work meetings, where spontaneity and accidental encounters may spark new ideas or provide an occasion for the extension of networks. 'Work has to be fun. Why bother to work so hard if it is not fun?' This is one of the most frequent heard statements of new media people. This playful attitude leads to an intensification of work. They listen to music while working, they do drugs while working, they spend a good deal of their work hours in pubs in cafes. And the purpose behind this integration of playfulness in work is to perform better.

Play is associated with creativity, experimentation, and innovation; it stands counterposed to bureaucracy and a protestant work ethic. Some commentators use the term 'playground' (Broeckmann, 1998; Schwarz, 2000) to describe the activities in the field of cultural industries and digital media. While play is intentional it involves the elaboration of non-purposive rationality (Gadamer, 1990). This is an activity which, while still rule-bound, is not subordinated to any pre-given aims or constrained by the developmental constraints of narrative. As such, it provides the basis of new symbolic resources in the workplace.

The assimilation of work and play corresponds with the blurring of boundaries between work and private life, between colleagues and friends, ${ }^{8}$ and between colleagues and clients. From my fieldwork in the London's new media industry it became clear that many firms established very close relationships with their clients. Both sides have to embark in a real collaboration. In these interactions, the boundaries between producer and client are fading. Sometimes the clients have been so deeply involved in the production process that they become part of the production team.

But the assimilation of work and play works in both directions. Not only is play invading work, we also experience the invasion of work into the realm of play. Parties, dinner parties, Carole Stone's monthly salon, SpeedDating, all this is strongly related to work. Networking events like First Tuesday, NetProZ and Chemistry can be seen as a perfect symbiosis of work and play, of instrumentality and non-purposive rationality. Parties for example work particularly well in combining both dimensions. This might be one of the

\footnotetext{
8 'It really pays to treat staff as if they are your friends', so the headline of an article in 'The Times' (27.7.2000).
} 
reasons for the popularity of parties in the cultural industries and in the new media field. Many new media companies, e.g. 'Pseudo' and 'Razorfish' have been well known for their parties. The 'Industry Standard', a San Francisco based new economy magazine, is 'famous for its Friday night parties' ('The Guardian', 9.1.2001: 3). Furthermore most of the new media conferences start and finish with a party. However all these parties are not just pure fun. Indeed they are hard work, as David Brooks (2000: 200-2) humorously describes.

Bobos (Bourgeois Bohemians, A.W.) have taken the ultimate symbol of Dionysian release, the party, and merged it with work... Now parties tend to be work parties; a glass or two of white wine, a little networking with editors and agents, and then it's home to the kids...More Bobos pass out business cards at parties than pass out under the table.

\section{Technology}

Network sociality is a technological sociality insofar as it is deeply embedded in communication technology, transport technology, and technologies to manage relationships. It is a sociality, that is based on the use of cars, trains, buses, and the underground, of airplanes, taxis, and hotels, ${ }^{9}$ and it is based on phones, faxes, answering machines, voicemail, videoconferencing, mobiles, email, chat rooms, discussion forums, mailing lists, and web sites. Transportation and communication technologies provide the infrastructure for people and societies on the move.

A community oriented sociality does not rely as much on transport and communication technology. Network sociality is delocalised, it is a sociality on the move, a sociality over distance, a sociality based on 'technogene Nähe', on technogenic closeness. (S. Beck, 2000) In this essay I have mainly focused on face-to-face sociality, however it is impossible to separate face-to-face interactions from interactions over distance. In urban spaces the idea of an uninterrupted face-to-face sociality, disentangled from technological devices is becoming the exeption. More and more we are experiencing an integration of long-distance communication in our realms of face-to-face interaction. Just consider the implications of advance of mobile phones in the last decade. It is hard to imagine a dinner of let's say four businessmen without a mobile ringing. The ringing mobile disrupts the previous social figuration and a new figuration has to be constructed. This new figuration however is transformational. It has to be renegotiated as soon as the conversation on the mobile is finished.

\footnotetext{
9 'The Observer' (4.7.1999: 7) recently warned that in terms of air traffic in the London area 'we will shortly be descending into chaos.' According to The Observer, Heathrow's two runways now handle an average of 85 aircraft every hour. Some 45 arrive and leave from Gatwick, 35 pass through Stanstead, Luton handles 20, London City 20 and Northolt in west London 12. 'All this adds up to 220 planes an hour, hitting runways once every 16 seconds.' According to The Observer, the air traffic in the London area will double in the next 20 years. If we assume an average passenger rate per plane of 200 (a rather low estimate), then there are currently more than one million passengers entering or leaving London every day. This is due to a massive rise of the tourism industry (Urry 1990), but maybe even more to the rise of business mobility. Pico Iyer (2000) recently published an ethnographic report about the effects of an increasing need for mobility. It is an exploration of life on the run and a world full of hotel, airports and shopping malls.
} 
The third form of technology necessary for the development of a network sociality are the technologies to manage social relationships, that is so say business cards, databases in email applications, and databases in mobile phones. Until recently, business cards have been the most popular mode to archive and order information about friends, colleagues, and acquaintances. However the weaknesses of business cards as technology to manage social relationships become increasingly apparent. Firstly and in stark contrast to databases they only allow for one system of order and categorisation (e.g. alphabetically, temporarily, according to profession). Secondly, business cards might be a helpful instrument to manage social relationships, but they don't guarantee that the owner of a business card collection will be able to relate all cards to persons or encounters. The size of the collection is particularly significant: the bigger the collection of cards, the more likely that the owner has to apply additional techniques to master the collection. Most of my interviewees have developed specific strategies to relate business cards to faces. One interviewee told me he writes on every new business card the date and the place of the encounter. Another person writes on the back of business cards one or two key words of the conversation she had. However all the people I talked to had something in common. They admitted that they have business cards they can't identify any more. It will be interesting to observe if the rise of the database will reduce the attractiveness of business cards.

\section{Conclusion}

I argue for the acknowledgement of an emerging model of sociality. The concept of network sociality is fairly incomplete however. So far networking as social practice is considerably under-researched, it lacks solid empirical data, and it especially needs ethnographic exploration. One of the areas under scrutiny would be the private-public dichotomy. How private and how public are these social bonds? Is it indeed feasible to conceptualise the private-public relation as dichotomy or could network sociality best be understood as a hybrid, as an amalgam of private and public aspects?

Another area that deserves empirical attention is the relation between different 'forms of capital' (economic, social, cultural, and symbolic). Bourdieu (1986) emphasises the convertibility of these different forms of capital. How is for example social capital transformed, transferred, translated, and exchanged into economic capital? How is the antagonism between functionality and morality renegotiated in network sociality? Finally, a third area worth being inspected more closely is the microdynamics of network relations. Aspects like trust, loyalty, hierarchy, power, and conflict need to be addressed and investigated in the context of networking. One strategy to improve an understanding of these aspects might consist in an attempt to re-examine sociological and anthropological studies of groups and to relate these findings to networking practices.

To conclude: My hypothesis is that network sociality will become the paradigmatic social form of late capitalism and the new cultural economy. After describing the phenomenon of the rise of networking as social practice and critically introducing three of the currently prominent theories of transformations of sociality, I have outlined my concept of a network sociality: it is a sociality based on individualisation and deeply embedded in technology; it is informational, ephemeral but intense, and it is characterised by an 
assimilation of work and play. Furthermore I suggest that certain features of the practice of networking might be 'new': its widespread practice in urban post-industrial spaces; its framing and institutionalisation in the form of new media networking events, parties, conferences, art openings, mailing lists and digital discussion forums; its increasing commodification and the increasing perception of social relationships as social capital; and finally a process from having relationships towards doing relationships and towards relationship management. Network sociality is about social bonds that are continuously produced, reproduced and - as Bauman (2000: 163) points out - 'consumed'.

In social science the assertion of novelty is always a tricky enterprise. Objections against such a perspective can easily be raised. Of course, all social changes contain elements of continuity. This cultural hypothesis of the rise of network sociality however has been developed in the spirit of the following remark by Castells (2000, Vol. 3: 356). 'After all, if nothing is new under the sun, why bother to try to investigate, think, write, and read about it?'

\section{References:}

Anderson, Benedict (1983) Imagined Community: Reflections on the Origin and Spread of Nationalism. New York: Verso.

Bauman, Zygmund (1996) 'Morality in the Age of Contingency', in P. Heelas, S. Lash and P. Morris (eds.) Detraditionalization: Critical Reflections on Authority and Identity. Oxford: Blackwell.

Bauman, Zygmund (1998) Globalization: The Human Consequences. Cambridge: Polity Press.

Bauman, Zygmund (2000) Liquid Modernity. Cambridge: Polity Press.

Beck, S. (ed.) (2000) Technogene Nähe. Berlin: Akademie Verlag.

Beck, Ulrich (1999) Individualization. London: Sage.

Beck, Ulrich, Giddens, Anthony and Lash, Scott (1994) Reflexive Modernisation:

Politics, Tradition and Aesthetics in the Modern Social Order. Cambridge: Polity Press.

Beck, Ulrich and Erdmann-Ziegler, Ulf (1997) Eigenes Leben. Ausflüge in die unbekannte Gesellschaft, in der wir leben. München: Beck.

Benson, Richard (1999) Flexecutives, The Guardian, 4.2.1999.

Berking, Helmut (1996) 'Solidarity Individualism: The Moral Impact of Cultural Modernisation in Late Modernity’ in S. Lash, B. Szerszynski and B. Wynne (eds.) Risk, Environment and Modernity. London: Sage.

Boden, Deirdre (1994) The Business of Talk: Organizations in Action. Cambridge: Polity Press.

Bourdieu, Pierre (1986) 'The forms of capital', in J.G. Richardson (ed.), Handbook of Theory and Research for the Sociology of Education. New York: Greenwood Press. 
Braidotti, Rosi (1994) Nomadic Subjects: Embodiment and Sexual Difference in Contemporary Feminist Theory. Columbia: Columbia University Press.

Broeckmann, Andreas (1998) 'Towards a European Media Culture - which Culture, which Media, which Europe?’ http://www.v2.nl/ andreas/texts/1998/europeanmediaen.html

Brooks, David (2000): Bobos in Paradise. The New Upper Class and how they Got there. New York: Simon \& Schuster.

Burt, Ronald (1980) 'Models of Network Structure’ Annual Review of Sociology 6: 79141.

Castells, Manuel (2000): The Information Age: Economy, Society and Culture. $2^{\text {nd }}$ edition. Volume 1, 2 and 3. Malden, MA: Blackwell.

Gadamer, Hans-Georg (1990) Wahrheit und Methode. Tübingen: Mohr.

Giddens, Anthony (1984) The Constitution of Society. Cambridge: Polity.

Giddens, Anthony (1990) The Consequences of Modernity. Cambridge: Polity.

Giddens, Anthony (2001) 'Anthony Giddens and Will Hutton in Conversation' in: W.

Hutton and A. Giddens (eds.) On the Edge: Living with Global Capitalism. London:

Vintage.

Goldwasser, A. (2000) 'Building Dilbert’s Dream House’ The New York Times Magazine, 5.3.2000, 68-71.

Granovetter, Mark (1985): 'Economic Action and Social Structure: The Problem of Embeddedness’ American Journal of Sociology 91/3: 481-510.

Hardt, Michael and Negri, Antonio (2000) Empire. Cambridge, MA: Harvard University Press.

Indergaard, Michael (2000) 'The Bullriders of Silicon Alley: New York Places its Bets' Paper presented at the annual meetings of the American Sociological Association, August 2000.

Iyer, Pico (2000) The Global Soul. Jet Lag, Shopping Malls, and the Search for Home. New York: Alfred Knopf.

Jones, S. (ed.) (1997) Virtual Culture. Identity and Communication in Cybersociety. London: Sage.

Kelly, Kevin (1999) New Rules for the New Economy: Ten Ways the Network Economy is Changing Everything. New York: Viking.

Knorr-Cetina, Karin (2000) 'Postsocial Theory’ in G. Ritzer and B. Smart (eds.), Handbook of Social Theory. London: Sage.

Kurnit, Scott (1997) Creating Virtual Communities: It's the relationship that matters. @NY.8.8.1997.

Lash, Scott (2001) Critique of Information. London: Sage. forthcoming

Lash, Scott and Urry, John (1994) Economies of Signs and Space. London: Sage. 
Latour, Bruno (1998) 'Thought Experiments in Social Science: from the Social Contract to Virtual Society' $1^{\text {st }}$ Virtual Society? annual public lecture, Brunel University, April 1998.

Leadbeater, Charles (1999) Living on Thin Air. The New Economy. London: Penguin.

Löfgren, Orvar (2001) 'European Ethnology and Life in the Experience Economy' Opening lecture at the $7^{\text {th }}$ SIEF-Conference, Budapest, April 2001.

Lury, Celia (1993) Cultural Rights. London: Routledge.

Mandel, Ernest (1973) Der Spaetkapitalismus. Frankfurt/Main: Suhrkamp.

Manovich, Lev (2001) The Language of New Media. Cambridge, MA: The MIT Press.

Miller, Daniel and Slater, Don (2000) The Internet. Oxford: Berg.

Nancy, Jean-Luc (1991) The Inoperative Community. Minneapolis: University of Minnesota Press.

OMA, Koolhaas, Rem and Mau, Bruce (1995): S,M,L,XL. Rotterdam: 010 Publishers.

Pourmehdi, M. (2000) 'Fragmented Ethnic Community in a Globalizing World', in P.

Kennedy (ed.) Second International Conference on Globalization, Culture and Everyday

Life, Vol. II, 119-136. Manchester: The Manchester Metropolitan University.

Poster, Mark (1995) The Second Media Age. Cambridge: Polity Press.

Pratt, Andy (1998) 'Making Digital Spaces: A Constructivist Critique of the Network Society’ Unpublished paper.

Rheingold, Howard (1994) The Virtual Community: Finding Connection in a Computerised World. London: Secker and Warburg.

Rifkin, Jeremy (2000) The Age of Access. London: Penguin Books.

Robbins, Kevin (1995) 'Cyberspace and the World We Live In’ in M. Featherstone and R. Burrows (eds.) Cyberspace, Cyberbodies, Cyberpunk. London: Sage.

Schulze, Gerhard (1993) Die Erlebnisgesellschaft: Kultursoziologie der Gegenwart. Frankfurt: Campus.

Schwarz, Michiel (2000) 'Digital Media in the Technological Culture - Perspectives for Arts and Cultural Policy’. Advice commissioned by the State Secretary for Education, Culture and Science of The Netherlands.

Scott, Allen (1997) 'The Cultural Economy of Cities' International Journal of Urban and Regional Research 21, 2: 323-340.

Sennett, Richard (1998) The Corrosion of Character. The Personal Consequences of Work in the New Capitalism. New York/London: W.W. Norton and Company.

Simmel, Georg (1911) 'Soziologie der Geselligkeit'. Schriften der deutschen Gesellschaft für Soziologie, vol. 1, 1-16.

Stone, Allucquere (1995) The War of Desire and Technology at the Close of the Mechanical Age. MIT Press: Cambridge, MA. 
Stone, Carole (2000) Networking: The Art of Making Friends. London: Vermilion.

Tönnies, Ferdinand (1979) Gemeinschaft und Gesellschaft. Grundbegriffe der reinen Soziologie. 8. Auflage. Darmstadt: Wissenschaftliche Buchgemeinschaft.

Touraine, Alain (1988) Return of the Actor. Social Theory in Postindustrial Society. Minneapolis: University of Minnesota Press.

Turkle, Sherry (1995) Life on the Screen: Identity in the Age of the Internet. New York: Simon \& Schuster.

Urry, John (1990) The Tourist Gaze: Leisure and Travel in Contemporary Societies. London: Sage.

Virilio, Paul (1995) Speed and Information. Cyberspace Alarm. CTHEORY, http://www.ctheory.com/a30-cyberspace_alarm.html

Williams, M. (2000) Who Says You Can’t Hurry Love. New York Times, 5.3.2000.

WIRED 8.06 (June 2000), Interview with Pehong Chen, p. 238.

Wittel, A., Lury, C. and Lash, S. (2002) Real and Virtual Connectivity: New Media in London. In Woolgar, S. (ed.) Virtual Society? Get Real! Oxford: Oxford University Press.

Zukin, Sharon (1995) The Cultures of Cities. Oxford: Blackwell. 